unfortunate Allies in the attempt to revive their astronomical journal. It will be issued once a month unless circumstances should enable it to appear more frequently. Subscriptions and correspondence should be sent to Felix de Roy, Hon. Sec., 29 Stamford Street, London, S.E.

\section{THE HARDENING OF METALS.}

A VISITOR at the recent meeting of the Faraday

Society could scarcely have failed to be struck by the fact that although the society was supposed to be discussing the hardening of metals, in reality the discussion centred almost entirely round the various theories of the hardening of steels. The reason for this was probably twofold. First, in spite of, or perhaps on account of, the considerable amount of research work that has been published on this problem it still remains the most keenly debated topic in metallurgical circles, and one on which widely different opinions have been held. Secondly, from a practical point of view it may be broadly stated that, in regard to hardening, steels are the only alloys that really matter.

Yet there can be no doubt that the council of the Faraday Society made a wise choice in the title of the topic for discussion. Even the simplest pure iron carbon steel is a complex material. Its complexity is due to the facts that (I) iron exists in at least two well-defined allotropic forms; (2) above $780^{\circ} \mathrm{C}$. it is non-magnetic; below it, magnetic; and (3) carbon has a remarkable tendency to form compounds of a high degree of molecular complexity. While considerable attention has been directed to the first two aspects of the matter, the third has not yet received the attention that it deserves, and will require before a complete solution of the problem can be reached. The position, therefore, is that while steels may be the most interesting alloys to investigate it does not follow that they are most suitable. What is first of all required is a fundamental investigation of the theory of the hardening of metals from which the foregoing disturbing causes are absent. When the foundations of this have been securely laid the precise effect of the above "variables" will no doubt be elucidated by suitably chosen experiments.

This aspect of the matter was clearly seen many years ago by Dr. G. T. Beilby, who has investigated the physical mechanism of the hardening of metals such as gold, silver, and copper, which can be obtained in a high state of purity, and from which magnetic and chemical complications are absent. Until quite recently it would have been possible to say that allotropic complications were also absent, and so far as present knowledge goes they were absent in the case of gold and silver. Recent investigations by Prof. Ernst Cohen (Utrecht), however, have led him to conclude that the metals cadmium, lead, bismuth, copper, zinc, and antimony ordinarily occur as metastable systems consisting of two or more allotropic forms, so that this consideration must be kept in view. Prof. Cohen was unfortunately unable to be present at the meeting, but an important summary of his results was available and is worthy of very close study. Ordinarily the transformations from one allotropic form to another are subject to strongly marked retardations, and it is only by employing certain devices such as the addition of an electrolyte and the use of the metal in a finely divided state that the transformation velocity can be increased to such an extent that the change from the metastable to the stable form occurs within a short time. These transformations are frequently accompanied by marked volume changes leading to complete disintegration of the metal.
These recent developments do not, however, alter the fact that Dr. Beilby chose for his investigations metals of the most suitable kind from the point of view of arriving at a physical conception of the mechanism of hardening by mechanical deformation, and they enabled him to prove the existence of a thermally stable crystalline and a mechanically stable amorphous vitreous phase in each metal investigated. How far-reaching and fundamental these conclusions have proved to be is evidenced by the fact that all the papers dealing with the hardening of steels presented at the meeting incorporated and made more or less use of them. According to Mr. Humfrey: "The hard structure which can be produced in carbon steels by quenching and in certain alloy steels by normal cooling is due to the presence of a hard, amorphous solution of $a$ iron and iron carbide." Mr. McCance's view is that the hardening is due to "interstrained" $a$ iron, and the suppression of the carbide change. The theory of Profs. Edwards and Carpenter is that the hardness is caused by the complete suppression of the carbide change, together with the presence of amorphous layers existing at the surfaces of slip upon which copious twinning occurs when carbon steels are quenched. On this view the final cause of hardening by quenching is exactly the same as that of hardening by cold working, viz., the internal deformation of the crystals.

When these theories are carefully examined it is significant to note how much they have in common. All of them agree that the carbide (Ar I) change is suppressed, a fact of very fundamental importance. The differences centre round the precise condition of the iron, and arise chiefly from differences in conclusions drawn from the magnetic condition of the alloy. They will not be adjusted until it has been settled whether iron can be magnetic in other than the a. condition. Mr. McCance apparently denies that the iron in hardened steels is amorphous. It is not yet clear precisely what he means by the term "interstrain," and how it differs, if at all, from the term "internal tension," suggested many years ago by Metcalf and Langley.

Most significant of all is the fact that none of the above theories make use of $\beta$ iron. This means that the controversy has essentially changed. It is no longer between the allotropists who laid chief stress on the postulated existence of a hard, stable, crystalline $\beta$ iron, which was held to be primarily responsible for the hardness of quenched steel, and the carbonists, who denied this altogether, and ascribed the hardness to the action of carbon without, however, being able to explain it. The complete solution of the problem now appears to be bound up with the acquisition of a more intimate knowledge of the molecular combinations between iron and carbon in hardened steels and their variations in the hardening range of temperature. Stimulus to investigations of this character will no doubt be given by the substantial prize offered by Sir Robert Hadfield, the president of the Faraday Society, for the best research dealing with the combinations between iron and carbon. He has rendered an important service in directing attention to this difficult but neglected side of the subject.

H. C. H. Carpenter.

AIR, CLIMATE, AND TUBERCULOSIS. ${ }^{1}$

T N October, $189 \mathrm{I}$, Thomas George Hodgkins, of Setauket, New York, made a donation to the Smithsonian Institution the income from a part of which was to be devoted to "the increase and diffusion of more exact knowledge in regard to the nature and

1 Smithsonian Miscellaneous Collections. Vol. lxiii., No. r. Hodgkins Fund. "Atmospheric Air in Relation to Tuberculosis." By Dr. G. Hinsdale. Pp. $x+136$. (Washington: Smithsonian Institution, 1914.) 